\title{
Closure of chronic non healing ankle ulcer with low level laser therapy in a patient presenting with thalassemia intermedia: Case report
}

\author{
Snehil Dixit, Parul Raj Agrawal', Dinesh Kumari Sharma ${ }^{2}$, Ravindra Pratap Singh ${ }^{3}$ \\ Department of Rehabilitation Sciences, College of Applied Medical Sciences, King Khalid University, ${ }^{1}$ Department of \\ Physiotherapy, School of Allied Health Sciences, ${ }^{2}$ Department of Prosthodontics, Manipal College of Dental Sciences, \\ ${ }^{3}$ Department of Community Medicine, Manipal University, Manipal, Karnataka, India
}

Address for correspondence: Dr. Snehil Dixit, Assistant Professor, Department of Rehabilitation Sciences, College of Applied Medical Sciences, King Khalid University, Saudi Arabia. E-mail: snehildixit83@gmail.com

\section{ABSTRACT}

In this single case study, the possible effect of low-level laser therapy (LLLT) was explored in the form of light emitting diodes on a chronic non-healing wound of 6 months duration in an 18-yearold male patient suffering from thalassemia intermedia. After irradiation, with LLLT dosage of 17.3 $\mathrm{J} / \mathrm{cm}^{2}$ for $8 \mathrm{~min}$ for 2 weeks duration followed by proliferative dosage of $8.65-4.33 \mathrm{~J} / \mathrm{cm}^{2}$ for $4 \mathrm{~min}$ from $3^{\text {rd }}$ week to $6^{\text {th }}$ week for 2 min along with antibiotics vancomycin $(15 \mathrm{mg} / \mathrm{kg})$ and a combination of amoxicillin and clavulanic acid $(1 \mathrm{~g})$. Proliferation of healthy granulation tissue was observed with decrease in score of pressure ulcer scale with complete re-epithelialization eventually LLLT irradiation could be a novel method of treatment for chronic non-healing wound in a thalassemia intermedia patient and an useful adjunct to standard care of treatment of pressure ulcers. It is postulated that LED irradiation augments wound healing with an early closure and no recurrence at the irradiated site even after follow up of 6 months.

\section{KEY WORDS}

Light emitting diodes; re-epithelialization; thalassemia; wound healing

\section{INTRODUCTION}

elayed wound healing is a complex phenomenon. The pattern of wound healing may be affected by cytokines, endocrines or manipulation of wound environment. The circumstance, in which the wound is

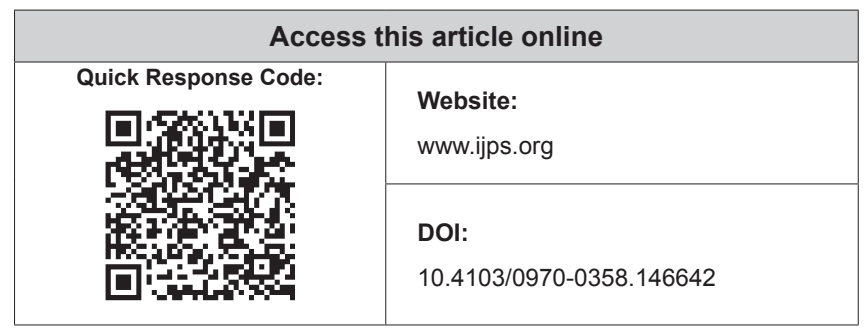

sustained, clearly influences wound bed infections with organisms. ${ }^{[1]}$

Occurrence of juvenile leg ulcers is relatively common in thalassemia intermedia. ${ }^{[2]}$ Usually, these ulcers are slow to heal and tend to reoccur frequently and affect the individual's day to day activities. ${ }^{[3]}$

Low-level laser therapy (LLLT) or simply "laser therapy" augments wound closure by secondary intention. The mechanism of action of laser on wound healing is postulated as modulation of inflammation by reducing the levels of pro-inflammatory cytokines and increasing the levels of anti-inflammatory growth factors. ${ }^{[4]}$ 


\section{CASE REPORT}

An 18-year-old male thalassemia intermedia patient presented with the history of chronic non-healing ulcer on the right ankle of 6 months duration, measuring $24 \mathrm{~cm}^{2}$. At the time of admission, patient was having a score of 12 for pressure ulcer scale for healing (PUSH) with generalized lymphadenopathy. Slough was seen in the wound bed with no exudate. Moderate growth of methicillin-resistant Staphylococcus aureus (MRSA) was isolated from the wound swab. LLLT in the form of light emitting diodes (LEDs) was commenced with dosage of $17.3 \mathrm{~J} / \mathrm{cm}^{2}$ for $8 \mathrm{~min}$ for 2 weeks duration followed by proliferative dosage of $8.65-4.33 \mathrm{~J} / \mathrm{cm}^{2}$ for $4 \mathrm{~min}$ from $3^{\text {rd }}$ week to $6^{\text {th }}$ week for 2 min along with antibiotics vancomycin $(15 \mathrm{mg} / \mathrm{kg})$, and a combination of amoxicillin and clavulanic acid $(1 \mathrm{~g})$.

Pressure ulcer scale for healing score decreased from $3^{\text {rd }}$ week to $10^{\text {th }}$ with a score of 0 on $6^{\text {th }}$ week with complete closure of the wound [Figure 1-5]. There was no recurrence seen at the site of post-irradiation on 6 months of follow-up.

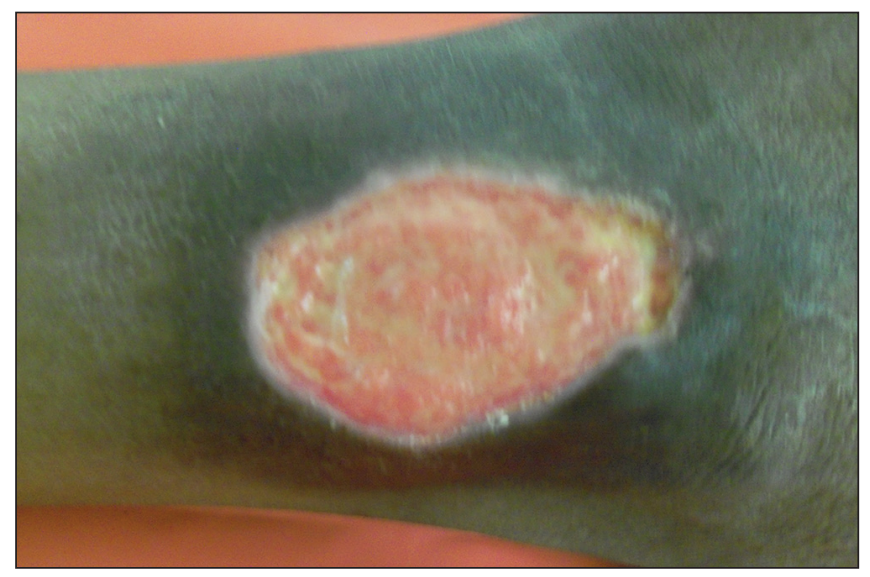

Figure 1: Wound at baseline

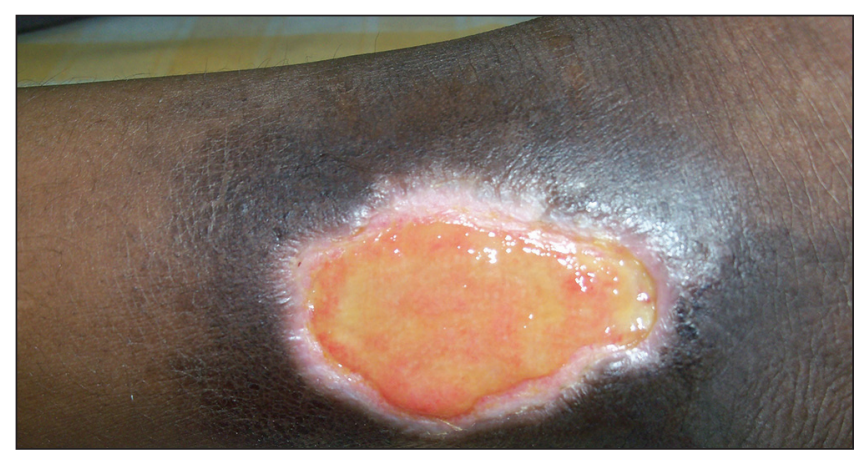

Figure 3: Changes in the wound bed after $3^{\text {rd }}$ week of irradiation
Investigations before the commencement of the therapy were as follows, the erythrocyte sedimentation rate was $9 \mathrm{~mm} / \mathrm{h}$, total white blood cells: $46,910 / \mu \mathrm{L}$, platelet count 899,010/ $\mu \mathrm{L}$, haemoglobin $(\mathrm{Hb}): 7.8 \mathrm{~g} / \mathrm{dL}$, red blood cell (RBC) count $3.33 \times 10^{6} / \mu \mathrm{L}$, red blood cell distribution width $27.8 \%$, and haematocrit value were $25.2 \%$; In peripheral smear report, RBC appeared microcytic hypochromic; anisopoikilocytosis and was positive for polychromatophils, spherocytes, schistocytes. The mean corpuscular volume was $75.8 \mathrm{fl} / \mathrm{cell}$, mean corpuscular haemoglobin concentration $30.8 \mathrm{~g} / \mathrm{dL}$, mean corpuscular hemoglobin $23.3 \mathrm{pg} / \mathrm{cell}$. Hb electrophoresis revealed $\mathrm{Hb}$ F-73\%; $\mathrm{Hb}$ A2-3\%; Hb A-24\%; the electrophoresis was suggestive of thalassemia intermedia. Ferritin more than $2000 \mathrm{ng} / \mathrm{mL}$, total iron binding capacity was $261 \mathrm{~g} / \mathrm{dL}$, total iron was $238 \mathrm{~g} / \mathrm{dL}$; folate more than $20 \mathrm{ng} / \mathrm{mL}$, Vitamin $B_{12}$ $388.6 \mathrm{pg} / \mathrm{mL}$; MRSA pathogen was also isolated from the wound area.

The patient was on vancomycin (15 mg/kg) and amoxicillin with clavulanic acid (1gm twice daily), and folate $(5 \mathrm{mg})$. Dressings were done with betadine and mupirocin $(2 \%[15 \mathrm{~g}])$. The patient was examined for any

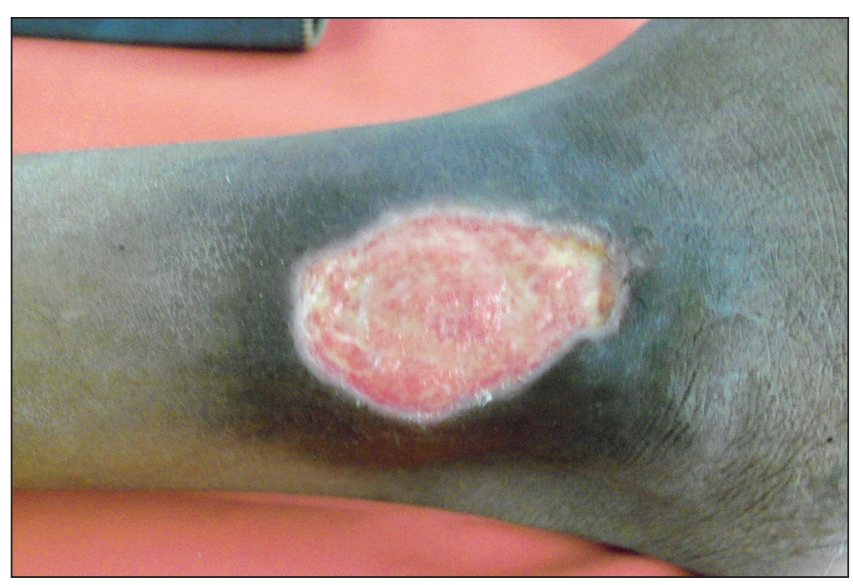

Figure 2: Wound bed after $1^{\text {st }}$ week of irradiation

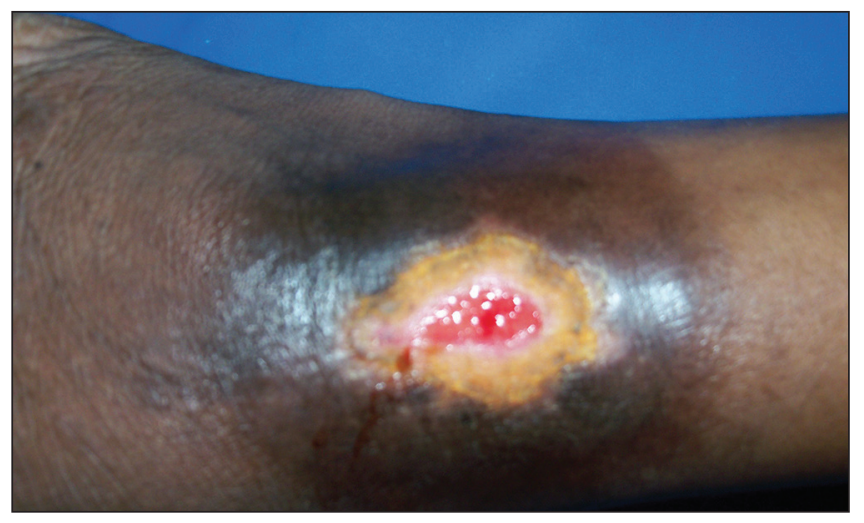

Figure 4: Contraction of wound bed after $4^{\text {th }}$ week of irradiation 


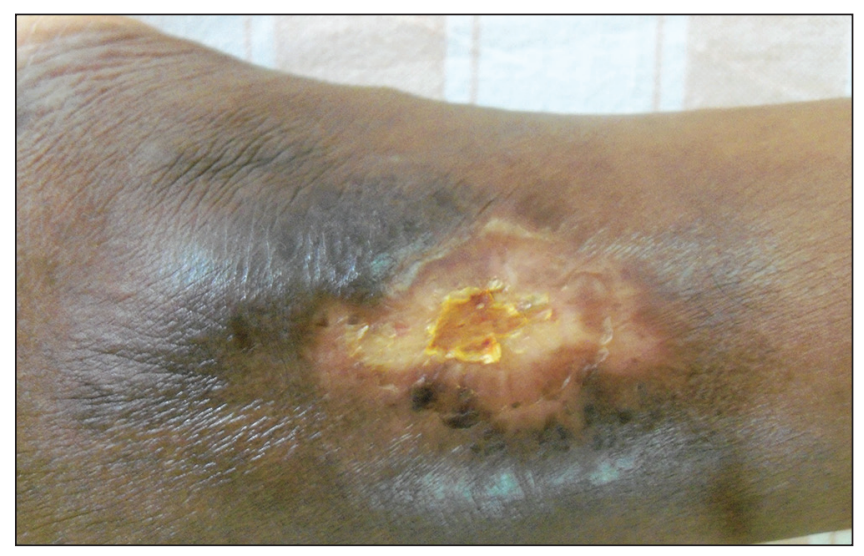

Figure 5: Complete closure at $6^{\text {th }}$ week of irradiation

possible absolute and relative contraindications with laser therapy at baseline. A written informed consent was obtained before starting laser therapy. The accuracy for the output dosage of the laser machine was tested prior to irradiation using specialized photodiode equipment (dosimeter). Due protection of the eyes with wavelengthspecific goggles and a comfortable semi reclining posture were maintained. Before beginning with the irradiation, the surrounding skin surface along the wound area was cleaned with betadine solution to enhance the absorption of laser in the wound area. The frequency of the irradiation was kept to once a day for 3 days/week until 6 weeks, and the dose was $17.3 \mathrm{~J} / \mathrm{cm}^{2}$ for $8 \mathrm{~min}$ for 2 weeks duration followed by proliferative dosage of $8.65-4.33 \mathrm{~J} / \mathrm{cm}^{2}$ for $4 \mathrm{~min}$ from $3^{\text {rd }}$ week to $6^{\text {th }}$ week for 2 min. $^{[4]}$

A hand-held class 4 LEDs (gallium aluminium arsenide; LX 2 model, manufactured by Thor) was used at a distance of $1 \mathrm{~cm}$ from the ulcer. The probe was a collection of 69 such LEDs, of which 34 LEDs were of a wavelength of $660 \mathrm{~nm}$ and had a spectral width of $50 \mathrm{~nm}$ at $50 \%$ intensity, the average power of $10 \mathrm{~mW}$, a spot size of $0.2 \mathrm{~cm}^{2}$ and a power density (irradiance) of $50 \mathrm{~mW} / \mathrm{cm}^{2}$. The remaining 35 LEDs were of wavelength of $950 \mathrm{~nm}$ with a spectral width of $50 \mathrm{~nm}$ at $50 \%$ intensity, generating a total power of $865 \mathrm{~mW}$ and a frequency of $156 \mathrm{~Hz}$.

The dosage for irradiation was decided according to the formula: $\mathrm{D}=\mathrm{P} \times \mathrm{T} / \mathrm{A},{ }^{[4,5]}$ where $\mathrm{D}$ is the dose in $\mathrm{J} / \mathrm{cm}^{2}$; $\mathrm{P}$ is the laser power output in watts, $T$ is the irradiation time in seconds and $\mathrm{A}$ is the area of the wound measured in $\mathrm{cm}^{2}$. LEDs were used for $8 \mathrm{~min}$, yielding an energy density for an antibiotic dosage of $17.3 \mathrm{~J} / \mathrm{cm}^{2}$ for 2 weeks followed by proliferative dosage of $8.65-4.33 \mathrm{~J} / \mathrm{cm}^{2}$ from $3^{\text {rd }}$ week (4 min) to $6^{\text {th }}(2 \mathrm{~min})$ week respectively.

\section{DISCUSSION}

It is now established that such clinical phenotypes lie in severity between those of thalassemia minor (clinically silent, mildly hypochromic and microcytic anaemia) and transfusion-dependent thalassemia major, are termed as thalassemia intermedia. Although it is often seen that there is substantial clinical overlap between the 3 conditions. ${ }^{[6]}$ Wound healing in thalassemia is a complex situation where dehiscent wounds are common. ${ }^{[6]}$ In the present case, a chronic wound of 6 months duration which was not responding to the standard medical care was irradiated using LEDs.

The PUSH tool is a quick, reliable tool to monitor the changes in pressure ulcer status over time. ${ }^{[7]}$ The patient was assessed according to PUSH and post-irradiation, there was a marked decrease in the score after $3^{\text {rd }}$ week with full closure by $6^{\text {th }}$ week.

Irradiation with laser therapy involves stimulation of certain growth factors and cytokines that orchestrate various stages of wound healing, resulting in an accelerated rate of granulation and re-epithelisation [Figure 1-5]. LEDs are postulated to generate both red and infrared laser radiations causing reduction in inflammation, increase blood flow to the tissues leading to the proliferation of endothelial cells thereby increasing the formation of new blood capillaries and hence faster granulation. ${ }^{[4]}$

Light-emitting diodes need to be differentiated from LLLT as beams generated by them are neither monochromatic nor coherent, but they have an advantage of treating a larger area using varying wavelengths in wound healing. ${ }^{[8]}$ LEDs are postulated to stimulate basic energy processes in the mitochondria (energy compartments) of each cell, particularly when near-infrared light is used to activate the wavelength-sensitive constituents inside the cell (chromophores, cytochrome systems). It has also been established in earlier studies that LEDs accelerate the process of wound healing. ${ }^{[5,9]}$ Though the exact mechanism responsible for wound closure in thalassemia still remains elusive. Still, lasers can be extremely cost effective and didactic in approach as a therapy towards chronic wounds in thalassemia as they induce healing in a short span of time and further elude patients from coming under tremendous economical obligation which is commonly seen with surgical alternatives. 


\section{CONCLUSION}

Irradiation with LED is a novel method of treatment of chronic wound in thalassemia intermedia, as irradiation with LED can result in complete healing in six weeks with no recurrence at the irradiated site even after follow-up of 6 months.

\section{REFERENCES}

1. Henry M, Thompson J. Wound healing and management. Clinical Surgery. $2^{\text {nd }}$ ed. London: Elsevier Saunders Limited; 2002. p. 105-13.

2. Gimmon Z, Wexler MR, Rachmilewitz EA. Juvenile leg ulceration in beta-thalassemia major and intermedia. Plast Reconstr Surg 1982;69:320-5.

3. Vagaskar SR, Fernandez RJ, Mistry FP. Leg ulcer in a case of thalassemia minor (a case report). J Postgrad Med 1989;35:120-1.

4. Dixit S, Maiya A, Umakanth S, Borkar S. Photobiomodulation of surgical wound dehiscence in a diabetic individual by low-level laser therapy following median sternotomy. Indian J Palliat Care
2013;19:71-5.

5. Dixit S, Maiya AG, Umakanth S, Shastry BA. Closure of non-healing chronic ulcer in Klippel-Trenaunay syndrome using low-level laser therapy. BMJ Case Rep 2012;10:1-4.

6. Taher AT, Musallam KM, Karimi M, El-Beshlawy A, Belhoul K, Daar S, et al. Overview on practices in thalassemia intermedia management aiming for lowering complication rates across a region of endemicity: The OPTIMAL CARE study. Blood 2010;115:1886-92.

7. Gardner SE, Hillis SL, Frantz RA. A prospective study of the PUSH tool in diabetic foot ulcers. J Wound Ostomy Continence Nurs 2011;38:385-93.

8. Sobanko JF, Alster TS. Efficacy of low-level laser therapy for chronic cutaneous ulceration in humans: A review and discussion. Dermatol Surg 2008;34:991-1000.

9. Whelan HT, Buchmann EV, Dhokalia A, Kane MP, Whelan NT, Wong-Riley MT, et al. Effect of NASA light-emitting diode irradiation on molecular changes for wound healing in diabetic mice. J Clin Laser Med Surg 2003;21:67-74.

How to cite this article: Dixit S, Agrawal PR, Sharma DK, Singh RP. Closure of chronic non healing ankle ulcer with low level laser therapy in a patient presenting with thalassemia intermedia: Case report. Indian J Plast Surg 2014;47:432-5.

Source of Support: Nil, Conflict of Interest: None declared.

Announcement

FEBRUARY $7^{\mathrm{TH}}-8^{\mathrm{TH}} 2015$

APSI Ethicon accredited course

Head and Neck reconstruction

Venue: Tata Medical Center Kolkata

Course coordinator Gautam Biswas

Phone 9163590963

E mail headneckrecon@gmail.com 